\title{
Radiation-attenuated schistosome vaccination - a brief historical perspective
}

\author{
Q. D. BICKLE* \\ Immunology Unit, Department of Infectious and Tropical Diseases, London School of Hygiene and Tropical Medicine, \\ Keppel Street, London WC1E 7HT, UK
}

(Received 23 December 2008; revised 2 February 2009; accepted 3 February 2009; first published online 30 March 2009)

\author{
SUMMARY
}

The high level of protection which can be induced by vaccination of a range of hosts, from rodents to primates, with live radiation-attenuated schistosome larvae offers great promise for development of a human schistosome vaccine. Studies of the irradiated vaccine models benefitted from significant funding during the 1970-90s and much was learned concerning the inducers, targets and mechanisms of immunity. Less progress was made in definition of the protective antigens involved. The application of new techniques for identifying membrane and secreted antigens has recently provided new vaccine candidates and a new impetus for schistosome vaccine development. This article is intended as an overview of some of the main lessons learned from the studies of the irradiated vaccines as a backdrop to renewed interest in schistosome vaccine development.

Key words: schistosomiasis, radiation attenuation, membrane antigens, secreted antigens, vaccine development.

\section{INTRODUCTION}

Schistosomiasis has been eradicated from a number of areas of the world through valiant integrated control measures based on snail control, drug treatment and environmental modification. In many other endemic areas morbidity has been dramatically reduced in recent times by treatment with praziquantel, the only drug now in widespread use (Fenwick and Webster, 2006). In such areas the snail host populations remain unaffected, transmission persists and reinfection is common. Relaxation of vigilance in 'eradicated' areas or of control efforts in endemic areas or development of resistance to praziquantel would rapidly lead to resurgence of the disease. Despite the potential of regular chemotherapy to control morbidity, the desirability of a vaccine to supplement and sustain chemotherapy-based control efforts remains as high as in 1970-1990 (Taylor, 1994) when schistosome vaccine research was reasonably well funded. A particular focus of attention during this time was on vaccination with radiation-attenuated larval infections which were demonstrated to be highly effective in many experimental hosts (Taylor, 1994) and this encouraged belief in the feasibility of developing a defined schistosome vaccine for humans. Further studies of irradiated vaccines yielded considerable understanding of the schistosome lifecycle stages which are the optimal inducers and targets of such immunity but limited progress was made

* Tel: +0207 927 2609. Fax: 0207323 5687/636 8739. E-mail: quentin.bickle@1shtm.ac.uk into defining and validating the protective antigens involved. Other, parallel approaches to vaccine development yielded several recombinant-derived schistosome proteins which showed promise in their labs of origin but less so when tested independently (Bergquist and Colley, 1998). With this, the impetus for vaccine development waned, particularly since there was a general perception in the public health community at this time that the schistosomiasis problem could be 'solved' globally using populationscale praziquantel treatment.

However, there is now a growing appreciation of the limitations of what chemotherapy campaigns alone can achieve, and recent application of proteomic and genomic techniques has facilitated the identification and characterization of membrane and secreted antigens, likely candidates for the protection induced by irradiated vaccines. So it is timely to review some of the lessons learned from the irradiated vaccine work in the hope of encouraging the new generation of those who share the belief that schistosome vaccines are both feasible and needed (Bergquist et al. 2005 ; Bethony et al. 2008). More exhaustive reviews of irradiated vaccines (Coulson, 1997; Dean, 1983) and of approaches to schistosome vaccine development (e.g. Hewitson et al. 2005; Wilson and Coulson, 2006; McManus and Loukas, 2008) are available.

IRRADIATED VACCINES - ESTABLISHMENT OF EFFECTIVE PROTOCOLS

Use of radiation-attenuated helminth infections to induce protection was first tested in the 1950 s and, 
notably, led to development of the commercial live vaccine Dictol ${ }^{\circledR}$ against Dictyocaulus viviparus, a nematode of cattle (Jarrett et al. 1958). The vaccine comprised oral infection with larvae irradiated with $40 \mathrm{krad}$ (kilorads) such that they did not reach the adult pathogenic stage but survived long enough to stimulate cells in the mesenteric lymph nodes. Prompted by this success irradiated vaccines against other helminths were soon being tested e.g. Miller (1978). In the case of schistosomes, doses of 3-4 krad of X-or $\gamma$-radiation were shown to prevent developing schistosome worms surviving to the adult pathogenic egg-laying stage while doses of $1-3 \mathrm{krad}$ resulted in persistence of a small proportion of stunted and generally sterile adults (Smithers, 1962). There followed various protection studies against S. mansoni and S. japonicum in mice and repeatedly exposed rhesus monkeys using cercariae exposed to relatively low levels of radiation (Hsu et al. 1962; Radke and Sadun, 1963; Sadun et al. 1964; Smithers, 1962; Villella et al. 1961) and most studies reported higher levels of partial protection to challenge with very low doses of radiation which allowed a small proportion of stunted worms to survive. These studies were carried out at a time when the prevailing notion, based on studies in rhesus monkeys harbouring unattenuated S. mansoni infections (Smithers and Terry, 1965, 1967), was that the adult worm is the prime stimulus to protection and that the schistosomula stages contribute little to the development of resistance. Thus, with respect to these early irradiated infections Smithers (1976) suggested that '.. the immunizing effect is predominantly due to the few stunted worms which survive the lethal effects of radiation'. However, Hsu et al. (1969), wishing to avoid inflammatory foci in the lung and liver due to death of immunizing larvae in these organs, tested highly irradiated (24 or $48 \mathrm{krad}$ ) cercariae of $S$. mansoni and S. japonicum which would arrest in the lung/skin. Both radiation doses resulted in high levels of protection in rhesus monkeys ( $>80 \%$ fewer worms than controls) especially after repeated $(>3)$ infections.

In the early 1970 s studies were initiated using the schistosome species of domestic animals, S. mattheei and $S$. bovis, which meant that vaccination efficacy could be assessed in natural hosts i.e. sheep and cattle. Initial studies in sheep using 1 or 2 exposures to $S$. mattheei larvae irradiated at 3 or $6 \mathrm{krad}$ were ineffective but high levels of partial protection $>70 \%$ could be induced following 4 vaccinations and comparable protection could be induced with percutaneously applied cercariae and intramuscularly injected in vitro-transformed schistosomula ('Taylor et al. 1976b). Similar protection could be induced against $S$. bovis in cattle with a single vaccination (Bushara et al. 1978). These studies culminated in a field trial in cattle of an $S$. bovis vaccine comprising a single intramuscular injection of schistosomula irradiated at $3 \mathrm{krad}$ (Majid et al. 1980). High partial protection to natural exposure was demonstrated and was followed by similar successful field testing of an irradiated, cryopreserved, schistosomula vaccine for S. japonicum in cattle and buffaloes, key hosts of this zoonotic schistosome species (Hsu et al. 1984).

In the case of the human schistosome species, S. mansoni, a similar approach was applied using baboons, regarded as a suitable model for human schistosomiais since these primates, unlike rhesus monkeys, are natural hosts of both $S$. mansoni and $S$. haematobium. However, repeated exposure to larvae given low doses of radiation did not induce significant protection (Taylor et al. 1976a). This failure prompted studies in mice and rats aimed at defining the key parameters for optimal vaccination protocols. It was soon established that for resistance induced by a single exposure of mice the dose of radiation had a significant effect. Both low doses of radiation, allowing parasite survival through to stunted adult worms, and very high doses, arresting the larvae in the skin, were poorly effective whereas significantly higher protection could be induced with optimal doses (56 krad (Minard et al. 1978a) or $20 \mathrm{krad}$ (Bickle et al. 1979c)). In both cases the effects of these optimal doses of radiation on the larvae were similar, resulting in a slight delay in the skin but eventual migration to and death in the lungs (Minard et al. 1978b; Bickle et al. 1979b; Mastin et al. 1983; Mangold and Dean, 1984). The reasons for the numerical difference in these optimal doses is not clear but since at this early time most subsequent studies in the USA, although not all (Reynolds and Harn, 1992), employed doses around $50 \mathrm{krad}$ and in the UK, $20 \mathrm{krad}$. In rats, $20 \mathrm{krad}$ also arrested S. mansoni larvae in the lungs and similarly proved to be an optimal dose (Ford et al. 1984a).

The superior protective efficacy of highly irradiated cercariae in mice led to renewed testing in baboons and, similarly, somewhat greater protection could be induced with optimally-irradiated infections. Thus, studies using S. haematobium (Sturrock et al. 1980; Webbe et al. 1982; Harrison et al. 1990) demonstrated high levels of protection $(\sim 90 \%)$ with multiple (2-3) exposures to $20 \mathrm{krad}$ cercariae whilst lower protection was obtained with $3 \mathrm{krad}$ or $60 \mathrm{krad}$ and significantly less with a single vaccination ( 30\%) (Harrison et al. 1990). Repeated exposure to highly irradiated cercariae was also protective against S. mansoni (Stek et al. 1981 b) and could be boosted by repeated exposures (Kariuki et al. 2004). Significant partial protection $(\sim 45 \%)$ was also demonstrated in chimpanzees, our closest primate relative (Eberl et al. 2001).

So, high levels of protection have been demonstrated in a wide variety of hosts against various schistosome species including the three major human species. Choice of optimal radiation dose and use of 
multiple vaccinations are more crucial for some species than others, notably primates.

\section{INDUCERS AND TARGETS OF IMMUNITY}

Nearly all of our further understanding of the mechanisms of immunity induced by irradiated infections has come from studies of S. mansoni in mice, and to some extent from rats. The fact that optimal doses of radiation result in migration to and death in the lungs focused attention on the immunogenicity of the lungstage schistosomula (LS) and led to experiments showing that irradiated LS introduced into the lungs via intravenous injection (Dean et al. 1981; Ford et al. $1984 a$ ), or into the skin (Coulson and Mountford, 1989) could confer immunity. Emphasis on the larval stages was further supported by the relative failure of irradiated 3- or 4-week-old worms (Dean et al. 1981) or unirradiated adult worm (single sex) infections to induce protection in mice (Bickle et al. 1979a)

The LS was also shown, in the majority of studies, to be the principal target of immunity in challenged animals. By recovery of parasites following mincing and incubation of tissue (Minard et al. 1978b; Stek et al. $1981 a$ ) by quantitative histology (Mastin et al. 1983; Von Lichtenberg et al. 1985) and most accurately by autoradiographic tracking in compressed organs (Dean et al. 1984; Wilson et al. 1986; Dean and Mangold, 1992) it was shown that migration of percutaneously applied challenge larvae to the lungs is delayed in vaccinated compared with naïve mice but otherwise comparable. Subsequently, a greater proportion of schistosomula are retained in the lungs of vaccinated mice and these gradually disappear between 2-5 + weeks post-infection (Wilson et al. 1986; Dean and Mangold, 1992). LS introduced by i.v. injection into the lungs of vaccinated rats (Ford et al. 1984b; McLaren et al. 1985) and mice (Mangold et al. 1986) were also highly susceptible to attrition although, in some experiments in mice, somewhat higher levels of resistance followed percutaneous challenge (Smythies et al. 1996; Coulson and Wilson, 1997) which the authors suggested indicates that the skin stage may help to initiate a recall response prior to lung attrition.

Histological studies of the response elicited by percutaneously applied challenge infections in vaccinated mice showed pronounced inflammatory foci around schistosomula in the skin and subsequently in the lungs (Von Lichtenberg et al. 1985), for example, by day 8 post-challenge there were $>10$-fold more lung foci in vaccinated compared with control mice. The cellular infiltration, comprising predominantly mononuclear cells, starts as soon as the larvae reach the lungs and peaks around 8 days after infection (Smythies et al. 1996). Cells accumulate within the blood vessel and between the vascular endothelium and the alveolar epithelium resulting, it is suggested, in the intravascular migration of the larvae being impeded. Certainly, with time, an increasing proportion of larvae occur within alveoli where they induce even more pronounced foci (Crabtree and Wilson, 1986). Although Von Lichtenberg et al. (1985) described damaged LS in vaccinated mice, Crabtree and Wilson (1986) found no evidence of parasite damage and this led to the notion that LS may not be killed within the lung but rather diverted from their intravascular migration into the alveoli and subsequently lost via the trachea and eventually the GI tract. This was supported by later studies showing that challenge LS recovered from lungs of vaccinated mice over the extended period of attrition showed normal viability when injected into naïve mice (Coulson and Wilson, 1988). Furthermore, radio-isotope labelled, challenge organisms in compressed lungs always appeared as discrete autoradiographic foci of equal intensity, unlike foci caused when radio-isotope labelled, heat-killed LS were injected into the lungs which became smaller and fainter with time (Dean and Mangold, 1992). The lack of evidence of in vivo death of LS is consistent with the demonstration that they are also insusceptible to immune damage in vitro by either antibody-or cell-mediated mechanisms (Moser et al. 1980; Sher et al. 1982b; Bickle and Ford, 1982; Ahmed et al. 1997).

\section{MECHANISMS OF IMMUNITY}

Initial investigations into the mechanisms of vaccineinduced resistance in rodents implicated the immune response since $\mathrm{B}$ cell-depleted mice and athymic mice and rats failed to develop resistance (Sher et al. $1982 a$; Ford et al. 1987 a). Both antibody and CD4 ${ }^{+}$ T-cell-mediated, IFN- $\gamma$-dependent effector mechanisms have been demonstrated, depending on the host species and the number of vaccinations.

In mice, larvae from a percutaneuosly applied, optimally irradiated infection undergo a protracted migration in the skin (Mangold and Dean, 1984), specifically in the skin draining lymph nodes (SLN), and release greater amounts of parasite antigen than unirradiated larvae (Mountford et al. 1988). This results in marked increases in cell number (Constant et al. 1990) and prolonged in vitro antigen-specific CD4 + ve cell proliferation which is followed some time later by similar events in the lungs and draining mediastinal lymph nodes as larvae migrate there (James et al. 1981; Lewis and Wilson, 1982; Pemberton et al. 1991). Initial percutaneous exposure to either normal or irradiated cercariae induces both Th1 (IFN- $\gamma$ and IL-2) and Th2 (IL-5 and IL-4) cytokine responses in the SLN (CauladaBenedetti et al. 1991) but these are more protracted with the irradiated infection and Th1 cytokines responses tend to increase preferentially at later time points (Pemberton et al. 1991). Th1-polarized 
cytokine production is more prominent in the spleen (Caulada-Benedetti et al. 1991; Pearce et al. 1991; Pemberton et al. 1991) and the lungs (Smythies et al. $1992 b$ ). Based on an extensive series of studies (reviewed by Coulson, 1997) Wilson and colleagues determined that the cells primed in the SLN enter the systemic circulation and are recruited as effector/ memory cells to the lung airways and draining mediastinal lymph nodes, this recruitment coinciding with cell accumulation around irradiated larvae reaching the lungs (Mastin et al. 1985). This cell recruitment to the lung is dependent on the vaccinating larvae reaching the lungs and is essential for optimal immunity since naïve mice parabiosed to vaccinated partners show transfer of antigen-specific cells to the spleen but not to the lung, and manifest lower resistance (mean 35\% lower) than their vaccinated partners (Coulson and Wilson, 1997). In contrast to the latter, the parabiosed mice are also unable to resist an intravenous challenge with LS which is consistent with the concept that optimally irradiated larvae result in 'arming' of the lung with cells able to respond rapidly to migrating LS (Wilson and Coulson, 1989). These experiments and others (Mountford et al. 1992) highlight the fact that the high levels of immunity which can be induced in mice by a single exposure to attenuated larvae crucially depend on a proportion of the larvae surviving to reach and die in the lungs.

\section{Cell-mediated immunity (CMI)}

A role for Th1-mediated immunity in mice exposed once to irradiated cercariae was first indicated by the failure to induce resistance in CMI-deficient P strain mice (James and Sher, 1983) and later confirmed by the observation that significantly lower resistance occurred if $\mathrm{CD} 4+$ cells were depleted at the time of challenge (Kelly and Colley, 1988; Vignali et al. $1989 a$ ). After challenge of vaccinated mice, bronchoalveolar lavage (BAL) cells increase markedly in the lung and IFN- $\gamma$ production from CD $4+$ cells dominates, peaking at day 14 as foci develop around challenge parasites (Smythies et al. 1992b). Marked increases in IFN- $\gamma$, IL-12 p40, TNF- $\alpha$, and iNOS mRNA expression occur (Wynn et al. 1994, 1995) and high levels of iNOS mRNA occur specifically in the parasite-associated inflammatory foci (Wynn et al. 1994). BAL cells also show highly elevated nitric oxide (NO) production to a challenge of LS administered i.v. (Coulson et al. 1998). However, experiments designed to determine the contribution of IFN- $\gamma$ and NO to protection in singly vaccinated mice have reached somewhat varied conclusions. Depletion of IFN- $\gamma$ during challenge with neutralizing monoclonal antibody has been reported to dramatically (Smythies et al. 1992a) or modestly (Wynn et al. 1994; Jankovic et al. 1999) reduce protection. Similarly IFN- $\gamma$ Receptor KO mice show marked reduction $(\sim 55 \%)$ in protection (Wilson et al. 1996) whereas IFN- $\gamma$ KO mice show a modest reduction (25\%) (Jankovic et al. 1999). Use of iNOS $\mathrm{KO}$ mice or inhibitors of $\mathrm{NO}$ production have led to the conclusion that $\mathrm{NO}$ plays a modest role (reducing protection by $\sim 30 \%$ ) (James et al. 1998; Wynn et al. 1994) or no significant role (Coulson et al. 1998) in protection. Overall, these studies support a significant if not dominant role for CMI in singly vaccinated mice but Hewitson et al. (2007) have recently questioned this since mice lacking CD154, which are deficient in both Th1 and $\mathrm{IgG}$ responses, fail to develop protection when the Th1 component is reconstituted by administration of IL-12.

\section{Antibody-mediated immunity}

Antibody contributes to immunity following single vaccination in mice since protection is significantly $(\sim 30-50 \%)$ lower in B-cell-deficient ( $\mu \mathrm{MT})$ compared with WT mice (Anderson et al. 1999; Jankovic et al. 1999) and transfer of serum from singly vaccinated WT donors restores $\mu \mathrm{MT}$ immunity to that in WT mice (Jankovic et al. 1999). Following repeated exposure of mice CMI becomes less important and antibody more so. CD4 + cell depletion has less effect on protection after double vaccination (Vignali et al. $1989 a)$ and, following multiple $(5 \times)$ vaccination, depletion has no effect which, together with much enhanced antibody levels, indicates that any CMI requirement is fully replaced by antibodymediated protection (Kelly and Colley, 1988). This is consistent with the demonstration by CauladaBenedetti et al. (1991) that following repeated $(3 \times)$ exposure Th2 cytokines are upregulated at the expense of Th1 cytokines. Repeat vaccination also leads to somewhat enhanced protection (Minard et al. 1978 a ; Richter et al. 1993 a ; Anderson et al. 1999; Jankovic et al. 1999) and to boosting of antibody titres (Delgado and McLaren, 1990; Caulada-Benedetti et al. 1991; Anderson et al. 1999; Jankovic et al. 1999). This boosting of the antibody response explains the increased protection since both occur in IFN- $\gamma \mathrm{KO}$ but not in B-cell-deficient mice (Anderson et al. 1999; Jankovic et al. 1999).

The ability of attenuated larval infections to induce protective antibody was demonstrated directly by passive transfer of protection with serum from rabbits vaccinated with $20 \mathrm{krad}$-irradiated cercariae (Ford et al. 1984b; Bickle et al. 1985). Homologous passive transfer of protection using sera from singly or multiply vaccinated rats indicated that antibody is the principal mediator of protection in rats (Ford et al. $1984 b, 1987 b$ ). Such serum transfer is equally or more effective at day 5 , when the larvae are in the lungs, than at the time of challenge, but less effective when the larvae reach the liver (Ford et al. 1984b; Bickle et al. 1985; Mangold and Dean, 1992). This demonstrates that irradiated vaccine-induced 
antibody is effective against LS which were first shown to be a target of immunity in passive transfer experiments using serum from rats infected with unattenuated larvae (Mangold and Knopf, 1981). Using a different strain of rat McLaren and Smithers (1985) found that passive transfer of vaccinated rat serum was effective at day 5 post-challenge but not at day 0 and was also effective against a challenge of LS delivered into the lung via tail vein injection if given on the same day but not $4+$ days later. This demonstration of the unique susceptibility of the lung stage is consistent with the observed lung-stage attrition of the challenge infection in vaccinated rats (Ford et al. 1984b). The protection was shown to be mediated by IgG2a (Ford et al. 1987 b), the major isotyope in rats (Bazin et al. 1974) and by $\operatorname{IgG}$ in rabbit serum (Mangold and Dean, 1992).

Homologous passive transfer in mice was first shown by Mangold and Dean (1986) (50-85\% transfer of the resistance of the donors). Successful transfer depended on the donor mice receiving repeat ( 2 or more) vaccinations and, for optimal protection, for the serum to be given at the lung stage (6-10 days post-challenge) rather than at the time of challenge. Similar results were obtained by Richter et al. (1993a) and for $S$. japonicum by Moloney and Webbe (1990). However, McLaren and Smithers (1988) who, in contrast to other workers (Mastin et al. 1983; Von Lichtenberg et al. 1985; Dean et al. 1984; Wilson et al. 1986; Dean and Mangold, 1992) had described challenge parasite attrition in the skin of vaccinated mice (Kamiya et al. 1987) reported markedly higher protection when serum was transferred at the skin rather than at the lung stage. Various studies have shown that IgG1, IgG2a and IgG2b are boosted following multiple vaccination of mice although IgG1 is the most prominent isotype (Delgado and McLaren, 1990; Caulada-Benedetti et al. 1991; Wynn et al. 1996). By passive transfer, IgG (Mangold and Dean, 1986) and specifically IgG1 (Delgado and McLaren, 1990) have been identified as protective isotypes but the non- $\mathrm{IgG}$ serum fraction has also been implicated (Jwo and LoVerde, 1989).

In primates, repeated exposures are needed to induce modest to high levels of protection and result in boosting of antigen-specific $\operatorname{IgG}$, levels of which correlate with protection (Harrison et al. 1990); Soisson et al. 1993; Yole et al. 1996). This indicates that antibody plays a major role in irradiated vaccine immunity in primates.

Regarding the mechanism of antibody-mediated attrition, mice vaccinated with repeat ( 2 or 3$)$ exposures and in which antibody is believed to play a key role, show essentially similar mononuclear cellrich foci around challenge LS in the lung (Vignali et al. $1988 a$; Kassim et al. 1992) as have been described for singly vaccinated mice (Crabtree and

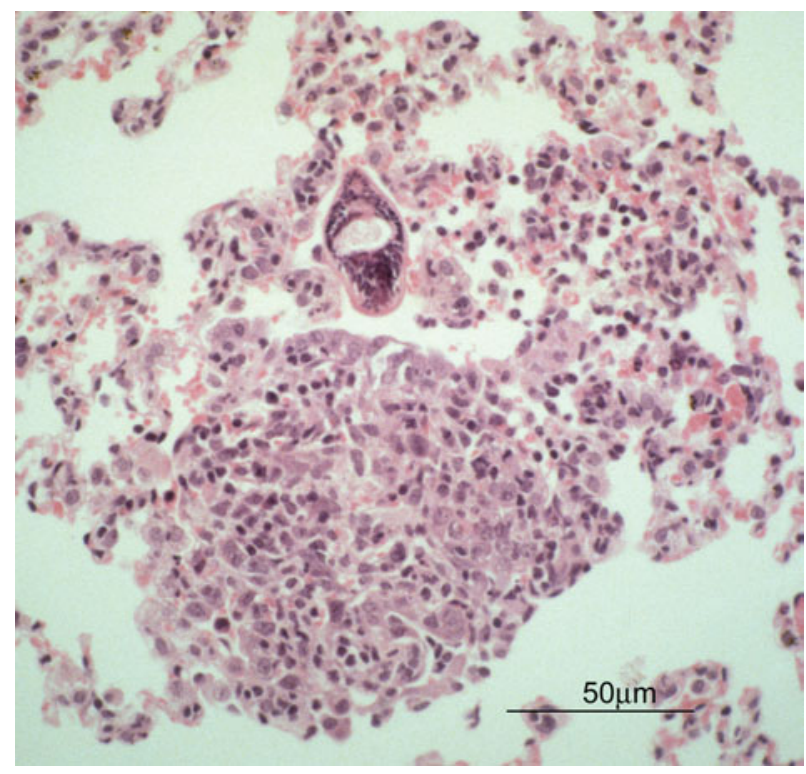

Fig. 1. Antibody-mediated mononuclear cell infiltration around a lung-stage schistosomulum induced by homologous passive transfer of vaccinated rat serum.

Wilson, 1986). Again the larvae appear undamaged and a proportion of them occur within alveoli, in which case they induce marked inflammatory responses (Kassim et al. 1992). McLaren and Smithers (1988) reported that transfer of immune serum at the skin stage elicited inflammatory reactions of mononuclear cells and eosinophils around schistosomula in the skin which, nevertheless, appeared morphologically similar to LS and so even in this model of apparent skin phase attrition, lung-form larvae appear to be the target. In rats, where there is consensus that challenge attrition occurs in the lungs of vaccinated animals (Ford et al. 1984b; McLaren et al. 1985) passive transfer of immune serum to naïve rats 5 days post-infection, when the challenge parasites are in the lungs, elicits an enhanced and accelerated inflammatory mononuclear cellular infiltration around the larvae compared with normal serum (Vignali et al. 1989b) as shown in Fig. 1. Because in mice there is no evidence of parasite damage or of intimate cellular attachment, cellular accumulation interfering with parasite migration (Crabtree and Wilson, 1986) is a plausible cause of parasite loss. How IgG is able to mediate such inflammatory foci is unknown. Protection occurs in $\mathrm{Fc} \gamma \mathrm{R}$ KO mice (Jankovic et al. 1999) and so Fc-receptor-mediated activation of cells for ADCC in not required. In rats, complement depletion during passive transfer at the lung stage significantly reduces protection (Vignali et al. 1988b) and so generation of the chemoattractants $\mathrm{C} 3 \mathrm{a}$ and $\mathrm{C} 5 \mathrm{a}$ by antibody/antigen fixation of complement may play a role in focus formation, at least in the rat. Other possible roles of antibody in interfering with parasite migration/viability by binding to surface receptors or signalling molecules remain to be assessed. 
THE ANTIGENS INVOLVED

Although not all studies agree, the weight of evidence from mice and rats is that the lung schistosomula alone can induce high levels of protection and that they are the only necessary targets eliciting cell- or antibody-mediated reactions during lung transit. It follows that the protective antigens are those responsible for the induction of lung foci such as shown in Fig. 1. Antigens responsible for $\mathrm{T}$ cell-mediated focus formation would be soluble or secreted antigens available to antigen presenting cells. Antibody could bind to such secreted antigens but could also bind to exposed epitopes of integral membrane antigens. Although the LS shows minimal surface antigenicity as judged by immunofluorescence (Pearce et al. 1986) sera from vaccinated animals can mediate transient cell adherence (Bickle and Ford, 1982; Lawson et al. 1993) indicating that antibody does have access to exposed larval antigens.

It follows that investigation of the vaccine potential of the secreted and membrane antigens of $\mathrm{LS}$ is a rational approach and soluble extract of in vitroderived LS is indeed able to induce significant protection in mice (Mountford et al. 1996). To characterize the LS antigens Harrop et al. (1999) used antisera against products released by such larvae in culture to screen Western blots of cercarial, LS and adult antigens. No LS-specific antigens were detected and when the sera were used to screen cDNA libraries most clones corresponded to previously described immunodominant antigens whose representation in the LS culture supernatant may have been due to release from damaged larvae. Cercariae, in vitro-derived schistosomula and adult worms are much more ready sources of antigen for study than in vivo-derived LS, but whether these stages share the protective LS antigens involved in irradiated vaccine immunity or whether these are transiently expressed during larval development in vivo is uncertain. However, strong protection $(\sim 90 \%)$ can be induced in mice with repeated $(5 \times)$ exposure to very highly irradiated (e.g. $100 \mathrm{krad}$ ) cercariae which die in the skin (Hsu et al. 1981) and comparable levels of protection to those demonstrated with LS (Mountford et al. 1996) can be induced with cercarial, in vitroderived schistosomula or adult antigens given with BCG intradermally (James et al. 1985). So the early larval and adult stages clearly manifest antigens which can induce protection. Recently, newer technologies for characterizing membrane and secreted antigens have been applied to analysis of schistosome adult worm proteins. Rigorous proteomic analysis has led to identification and characterization of a large number of adult tegumental (Braschi et al. 2006) and surface-associated (Braschi and Wilson, 2006) proteins. Cloning of genes with signal sequences has allowed identification of adult proteins targeted for secretion or surface expression (Smyth et al. 2003). Application of such methods has recently led to identification of tegumental proteins able to induce protection in mice e.g. the tetraspanins, TSP1 and TSP-2 (Tran et al. 2006) and Sm29 (Cardoso et al. 2008). Their involvement in irradiated vaccine immunity and exposure on the surface of living worms remains to be established although Sm29 has been shown to be expressed by the LS tegument (Cardoso et al. 2008).

Various approaches have been applied to identify antigens specifically recognized by vaccinated animals e.g. characterizing larval surface antigens recognized by vaccine serum (Simpson et al. 1983); generating monoclonal antibodies against larval surface antigens using vaccinated donors (Bickle et al. 1986; Dalton et al. 1987); testing known recombinant-derived antigens for reactivity with antibody or cells from vaccinated mice (Richter and Harn, 1993; Richter et al. 1993 b); identification of recombinant-derived antigens uniquely or preferentially recognized by irradiated vaccine serum (compared with infection serum) (Soisson et al. 1992; Francis and Bickle, 1992). Some of these antigens were included in the independent vaccine testing (Bergquist and Colley, 1998) but others remain to be characterized and tested. Amongst these are larval surface antigens uniquely recognized by vaccine serum but not by infection serum, e.g. $15 \mathrm{kDa}$ (Simpson et al. 1983) and $16 \mathrm{kDa}$ (Bickle et al. 1986) antigens and which appear to have transient expression in the larval stages (Bickle and Oldridge, 1999). Definition of such larval surface antigens will likely need application of those techniques so successfully applied to the adult tegument. It should be noted that it is not yet clear whether any of the above antigens or the many other schistosome antigens identified by other means, play a significant role in irradiated vaccine-induced immunity and specifically in mediating lung focus formation.

\section{PROSPECTS FOR A DEFINED VACCINE}

The evidence from the irradiated vaccine models suggests that provided the immunogenic moieties can be produced, protective immune responses may not be particularly challenging to induce. Thus, although WT mice, which make a balanced Th1/Th2 response, develop optimal immunity, high partial protection occurs in cytokine KO mice whether Th1 or Th2-polarized responses are induced (Hoffmann et al. 1999).

To simulate the antibody-mediated protection induced by irradiated vaccines IgG antibodies will be needed rather than $\mathrm{IgE}$ antibodies which are implicated in naturally-acquired resistance in humans (Hagan et al. 1998). Longevity of sufficiently high antibody titre will be a requirement. Based on irradiated vaccine studies in various host species, immunizing regimens which are believed to induce 
antibody-mediated immunity have been shown to lead to long-lived protection (Dean 1983; Hsu et al. 1981 ; Bickle et al. 1979d; Ford et al. 1984a) although some decline in protection with time has been shown in baboons (Harrison et al. 1990).

A vaccine aimed at reproducing the CMI mechanisms which help mediate protection in singly vaccinated mice faces a number of challenges. It would need to induce the lung sensitization required for optimal immunity in this model and this is likely to require targeting vaccine delivery to the lung as proposed, for example, for TB vaccines (Kallenius et al. 2007). It would need to induce Th1 responses but avoid over-induction of regulatory cytokines e.g. IL-10, since this can prevent manifestation of resistance (Oswald et al. 1998). Challenge exposure downregulates the Th1 response in mice (Pemberton and Wilson, 1995) and in the likely event of a vaccine inducing only partial protection the ensuing egg production is likely to profoundly alter the response from a Th-1 to a Th2-dominated response, as occurs when schistosome eggs are injected into vaccinated mice (Pearce et al. 1991). Furthermore, in endemic areas, vaccinees are likely to have an underlying Th2 biased response due to other worm infections or to previously treated schistosome infections that could interfere with the generation of Th1 responses. Regarding the influence of current/previous infection on vaccine efficacy it is encouraging that studies in baboons have shown that multiple irradiated vaccine regimens, likely to induce antibody-mediated protection, are equally effective in naïve and in infected or infected and previously treated animals (Kariuki et al. 2006).

Given the availability of a new crop of promising protective antigens and the enthusiastic application of new technologies for indentifying membrane and secreted antigens a schistosome vaccine modelled on the irradiated vaccine seems increasingly technically feasible. However, as Loukas et al. (2007) urged, development of this promise into a human vaccine will require the wheel to turn and significant investment to return to schistosome vaccine development.

I am very grateful to Martin Taylor and Helena Helmby for critical review of this manuscript.

\section{REFERENCES}

Ahmed, S. F., Oswald, I. P., Caspar, P., Hieny, S., Keefer, L., Sher, A. and James, S. L. (1997). Developmental differences determine larval susceptibility to nitric oxide-mediated killing in a murine model of vaccination against Schistosoma mansoni. Infection and Immunity 65, 219-226.

Anderson, S., Coulson, P. S., Ljubojevic, S., Mountford, A. P. and Wilson, R. A. (1999). The radiation-attenuated schistosome vaccine induces high levels of protective immunity in the absence of B cells. Immunology 96, 22-28.
Bazin, H., Beckers, A. and Querinjean, P. (1974).

Three classes and four (sub)classes of rat immunoglobulins: IgM, IgA, IgE and IgG1, IgG2a, $\mathrm{IgG} 2 \mathrm{~b}, \mathrm{IgG} 2 \mathrm{c}$. European Fournal of Immunology 4, 44-48.

Bergquist, N. R. and Colley, D. G. (1998). Schistosomiasis vaccine: research to development. Parasitology Today 14, 99-104.

Bergquist, N. R., Leonardo, L. R. and Mitchell, G. F. (2005). Vaccine-linked chemotherapy: can schistosomiasis control benefit from an integrated approach? Trends in Parasitology 21, 112-117.

Bethony, J. M., Diemert, D. J., Oliveira, S. C. and Loukas, A. (2008). Can schistosomiasis really be consigned to history without a vaccine? Vaccine $\mathbf{2 6}$, 3373-3376.

Bickle, Q., Bain, J., McGregor, A. and Doenhoff, M. (1979a). Factors affecting the acquisition of resistance against Schistosoma mansoni in the mouse: III. The failure of primary infections with cercariae of one sex to induce resistance to reinfection. Transactions of the Royal Society of Tropical Medicine and Hygiene 73, 37-41.

Bickle, Q. D., Andrews, B. J., Doenhoff, M. J., Ford, M. J. and Taylor, M. G. (1985). Resistance against Schistosoma mansoni induced by highly irradiated infections: studies on species specificity of immunization and attempts to transfer resistance. Parasitology $\mathbf{9 0 ,}$ 301-312.

Bickle, Q. D., Andrews, B. J. and Taylor, M. G. (1986). Schistosoma mansoni: characterization of two protective monoclonal antibodies. Parasite Immunology 8, 95-107.

Bickle, Q. D., Dobinson, T. and James, E. R. (1979b). The effects of gamma-irradiation on migration and survival of Schistosoma mansoni schistosomula in mice. Parasitology 79, 223-230.

Bickle, Q. D. and Ford, M. J. (1982). Studies on the surface antigenicity and susceptibility to antibodydependent killing of developing schistosomula using sera from chronically infected mice and mice vaccinated with irradiated cercariae. Fournal of Immunology 128, 2101-2106.

Bickle, Q. D. and Oldridge, J. (1999). Characterization of a stage-specific Mr16000 schistosomular surface glycoprotein antigen of Schistosoma mansoni. Molecular and Biochemical Parasitology 100, 85-94.

Bickle, Q. D., Taylor, M. G., Doenhoff, M. J. and Nelson, G. S. $(1979 c)$. Immunization of mice with gamma-irradiated intramuscularly injected schistosomula of Schistosoma mansoni. Parasitology 79, 209-222.

Bickle, Q. D., Taylor, M. G., James, E. R., Nelson, G. S., Hussein, M. F., Andrews, B. J., Dobinson, A. R. and Marshall, T. F. $(1979 d)$. Further observations on immunization of sheep against Schistosoma mansoni and S. bovis using irradiationattenuated schistosomula of homologous and heterologous species. Parasitology 78, 185-193.

Braschi, S., Borges, W. C. and Wilson, R. A. (2006). Proteomic analysis of the schistosome tegument and its surface membranes. Memórias do Instituto Oswaldo Cruz 101 (Suppl. 1), 205-212. 
Braschi, S. and Wilson, R. A. (2006). Proteins exposed at the adult schistosome surface revealed by biotinylation. Molecular and Cellular Proteomics 5, 347-356.

Bushara, H. O., Hussein, M. F., Saad, A. M., Taylor, M. G., Dargie, J. D., Marshall, T. F. and Nelson, G. S. (1978). Immunization of calves against Schistosoma bovis using irradiated cercariae of schistosomula of $S$. bovis. Parasitology 77, 303-311.

Cardoso, F. C., Macedo, G. C., Gava, E., Kitten, G. T., Mati, V. L., De Melo, A. L., Caliari, M. V., Almeida, G. T., Venancio, T. M., Verjovski-Almeida, S. and Oliveira, S. C. (2008). Schistosoma mansoni tegument protein Sm29 is able to induce a Th1-type of immune response and protection against parasite infection. PLoS Neglected Tropical Diseases 2, e308.

Caulada-Benedetti, Z., Al-Zamel, F., Sher, A. and James, S. (1991). Comparison of Th1 - and Th2associated immune reactivities stimulated by single versus multiple vaccination of mice with irradiated Schistosoma mansoni cercariae. Fournal of Immunology 146, 1655-1660.

Constant, S. L., Mountford, A. P. and Wilson, R. A. (1990). Phenotypic analysis of the cellular responses in regional lymphoid organs of mice vaccinated against Schistosoma mansoni. Parasitology 101, 15-22.

Coulson, P. S. (1997). The radiation-attenuated vaccine against schistosomes in animal models : paradigm for a human vaccine? Advances in Parasitology 39, 271-336.

Coulson, P. S. and Mountford, A. P. (1989). Fate of attenuated schistosomula administered to mice by different routes, relative to the immunity induced against Schistosoma mansoni. Parasitology 99, 39-45.

Coulson, P. S., Smythies, L. E., Betts, C., Mabbott, N. A., Sternberg, J. M., Wei, X. G., Liew, F. Y. and Wilson, R. A. (1998). Nitric oxide produced in the lungs of mice immunized with the radiation-attenuated schistosome vaccine is not the major agent causing challenge parasite elimination. Immunology 93, 55-63.

Coulson, P. S. and Wilson, R. A. (1988). Examination of the mechanisms of pulmonary phase resistance to Schistosoma mansoni in vaccinated mice. American Fournal of Tropical Medicine and Hygiene 38, 529-539.

Coulson, P. S. and Wilson, R. A. (1997). Recruitment of lymphocytes to the lung through vaccination enhances the immunity of mice exposed to irradiated schistosomes. Infection and Immunity 65, 42-48.

Crabtree, J. E. and Wilson, R. A. (1986). The role of pulmonary cellular reactions in the resistance of vaccinated mice to Schistosoma mansoni. Parasite Immunology 8, 265-285.

Dalton, J. P., Tom, T. D. and Strand, M. (1987). Cloning of a cDNA encoding a surface antigen of Schistosoma mansoni schistosomula recognized by sera of vaccinated mice. Proceedings of the National Academy of Sciences, USA 84, 4268-4272.

Dean, D. A. (1983). Schistosoma and related genera: acquired resistance in mice. Experimental Parasitology 55, 1-104.

Dean, D. A., Cioli, D. and Bukowski, M. A. (1981). Resistance induced by normal and irradiated Schistosoma mansoni: ability of various worm stages to serve as inducers and targets in mice. American Fournal of Tropical Medicine and Hygiene 30, 1026-1032.
Dean, D. A. and Mangold, B. L. (1992). Evidence that both normal and immune elimination of Schistosoma mansoni take place at the lung stage of migration prior to parasite death. American Fournal of Tropical Medicine and Hygiene 47, 238-248.

Dean, D. A., Mangold, B. L., Georgi, J. R. and Jacobson, R. H. (1984). Comparison of Schistosoma mansoni migration patterns in normal and irradiated cercaria-immunized mice by means of autoradiographic analysis. Evidence that worm elimination occurs after the skin phase in immunized mice. American Fournal of Tropical Medicine and Hygiene 33, 89-96.

Delgado, V. and McLaren, D. J. (1990). Evidence for enhancement of IgG1 subclass expression in mice polyvaccinated with radiation-attenuated cercariae of Schistosoma mansoni and the role of this isotype in serum-transferred immunity. Parasite Immunology 12, $15-32$.

Eber1, M., Langermans, J. A., Frost, P. A., Vervenne, R. A., Van Dam, G. J., Deelder, A. M., Thomas, A. W., Coulson, P. S. and Wilson, R. A. (2001). Cellular and humoral immune responses and protection against schistosomes induced by a radiation-attenuated vaccine in chimpanzees. Infection and Immunity $\mathbf{6 9}$, 5352-5362.

Fenwick, A. and Webster, J. P. (2006). Schistosomiasis: challenges for control, treatment and drug resistance. Current Opinion in Infectious Diseases 19, 577-582.

Ford, M. J., Bickle, Q. D. and Taylor, M. G. (1984a). Immunization of rats against Schistosoma mansoni using irradiated cercariae, lung schistosomula and liver-stage worms. Parasitology 89, 327-344.

Ford, M. J., Bickle, Q. D. and Taylor, M. G. (1987a). Immunity to Schistosoma mansoni in congenitally athymic, irradiated and mast cell-depleted rats. Parasitology 94, 313-326.

Ford, M. J., Bickle, Q. D., Taylor, M. G. and Andrews, B. J. (1984b). Passive transfer of resistance and the site of immune-dependent elimination of the challenge infection in rats vaccinated with highly irradiated cercariae of Schistosoma mansoni. Parasitology 89, 461-482.

Ford, M. J., Dissous, C., Pierce, R. J., Taylor, M. G., Bickle, Q. D. and Capron, A. (1987b). The isotypes of antibody responsible for the 'late' passive transfer of immunity in rats vaccinated with highly irradiated cercariae. Parasitology 94, 509-522.

Francis, P. and Bickle, Q. (1992). Cloning of a $21 \cdot 7-\mathrm{kDa}$ vaccine-dominant antigen gene of Schistosoma mansoni reveals an EF hand-like motif. Molecular and Biochemical Parasitology 50, 215-224.

Hagan, P., Ndhlovu, P. D. and Dunne, D. W. (1998). Schistosome immunology: more questions than answers. Parasitology Today 14, 407-412.

Harrison, R. A., Bickle, Q. D., Kiare, S., James, E. R., Andrews, B. J., Sturrock, R. F., Taylor, M. G. and Webbe, G. (1990). Immunization of baboons with attenuated schistosomula of Schistosoma haematobium: levels of protection induced by immunization with larvae irradiated with 20 and $60 \mathrm{krad}$. Transactions of the Royal Society of Tropical Medicine and Hygiene 84, 89-99.

Harrop, R., Coulson, P. S. and Wilson, R. A. (1999). Characterization, cloning and immunogenicity of 
antigens released by lung-stage larvae of Schistosoma mansoni. Parasitology 118, 583-594.

Hewitson, J. P., Hamblin, P. A. and Mountford, A. P. (2005). Immunity induced by the radiation-attenuated schistosome vaccine. Parasite Immunology 27, 271-280.

Hewitson, J. P., Hamblin, P. A. and Mountford, A. P. (2007). In the absence of CD154, administration of interleukin-12 restores Th1 responses but not protective immunity to Schistosoma mansoni. Infection and Immunity 75, 3539-3547.

Hoffmann, K. F., James, S. L., Cheever, A. W. and Wynn, T. A. (1999). Studies with double cytokinedeficient mice reveal that highly polarized Th1 - and Th2-type cytokine and antibody responses contribute equally to vaccine-induced immunity to Schistosoma mansoni. Fournal of Immunology 163, 927-938.

Hsu, H. F., Hsu, S. Y. and Osborne, J. W. (1962). Immunization against Schistosoma japonicum in rhesus monkeys produced by irradiated cercariae. Nature, London 194, 98-99.

Hsu, S. Y., Hsu, H. F. and Burmeister, L. F. (1981). Schistosoma mansoni: vaccination of mice with highly x-irradiated cercariae. Experimental Parasitology 52, 91-104.

Hsu, S. Y., Hsu, H. F. and Osborn, J. W. (1969). Immunization of rhesus monkeys against schistosome infection by cercariae exposed to high doses of $\mathrm{x}$-radiation. Proceedings of the Society of Experimental Biology and Medicine 131, 1146-1149.

Hsu, S. Y., Xu, S. T., He, Y. X., Shi, F. H., Shen, W., Hsu, H. F., Osborne, J. W. and Clarke, W. R. (1984). Vaccination of bovines against schistosomiasis japonica with highly irradiated schistosomula in China. American Fournal of Tropical Medicine and Hygiene 33, 891-898.

James, S. L., Cheever, A. W., Caspar, P. and Wynn, T. A. (1998). Inducible nitric oxide synthase-deficient mice develop enhanced type 1 cytokine-associated cellular and humoral immune responses after vaccination with attenuated Schistosoma mansoni cercariae but display partially reduced resistance. Infection and Immunity 66, 3510-3518.

James, S. L., Labine, M. and Sher, A. (1981). Mechanisms of protective immunity against Schistosoma mansoni infection in mice vaccinated with irradiated cercariae. I. Analysis of antibody and T-lymphocyte responses in mouse strains developing differing levels of immunity. Cellular Immunology 65, 75-83.

James, S. L., Pearce, E. J. and Sher, A. (1985). Induction of protective immunity against Schistosoma mansoni by a non living vaccine. I. Partial characterization of antigens recognized by antibodies from mice immunized with soluble schistosome extracts. Fournal of Immunology 134, 3432-3438.

James, S. L. and Sher, A. (1983). Mechanisms of protective immunity against Schistosoma mansoni infection in mice vaccinated with irradiated cercariae III. Identification of a mouse strain, $\mathrm{P} / \mathrm{N}$, that fails to respond to vaccination. Parasite Immunology $\mathbf{5}$, 567-575.

Jankovic, D., Wynn, T. A., Kullberg, M. C., Hieny, S., Caspar, P., James, S., Cheever, A. W. and Sher, A. (1999). Optimal vaccination against Schistosoma mansoni requires the induction of both $\mathrm{B}$ cell- and
IFN-gamma-dependent effector mechanisms. Fournal of Immunology 162, 345-351.

Jarrett, W. F., Jennings, F. W., McIntyre, W., Mulligan, W. and Urquhart, G. M. (1958). Irradiated helminth larvae in vaccination. Proceedings of the Royal Society of Medicine 51, 743-744.

Jwo, J. and LoVerde, P. T. (1989). The ability of fractionated sera from animals vaccinated with irradiated cercariae of Schistosoma mansoni to transfer immunity to mice. Fournal of Parasitology 75, 252-260.

Kallenius, G., Pawlowski, A., Brandtzaeg, P. and Svenson, S. (2007). Should a new tuberculosis vaccine be administered intranasally? Tuberculosis 87, 257-266.

Kamiya, H., Smithers, S. R. and McLaren, D. J. (1987). Schistosoma mansoni: autoradiographic tracking studies of isotopically-labelled challenge parasites in naive and vaccinated $\mathrm{CBA} / \mathrm{Ca}$ mice. Parasite Immunology 9, 515-529.

Kariuki, T. M., Farah, I. O., Yole, D. S., Mwenda, J. M., Van Dam, G. J., Deelder, A. M., Wilson, R. A. and Coulson, P. S. (2004). Parameters of the attenuated schistosome vaccine evaluated in the olive baboon. Infection and Immunity 72, 5526-5529.

Kariuki, T. M., Van Dam, G. J., Deelder, A. M., Farah, I. O., Yole, D. S., Wilson, R. A. and Coulson, P. S. (2006). Previous or ongoing schistosome infections do not compromise the efficacy of the attenuated cercaria vaccine. Infection and Immunity 74, 3979-3986.

Kassim, O. O., Dean, D. A., Mangold, B. L. and Von Lichtenberg, F. (1992). Combined microautoradiographic and histopathologic analysis of the fate of challenge Schistosoma mansoni schistosomula in mice immunized with irradiated cercariae. American Fournal of Tropical Medicine and Hygiene 47, 231-237.

Kelly, E. A. and Colley, D. G. (1988). In vivo effects of monoclonal anti-L3T4 antibody on immune responsiveness of mice infected with Schistosoma mansoni. Reduction of irradiated cercariae-induced resistance. Fournal of Immunology 140, 2737-2745.

Lawson, B. W., Bickle, Q. D. and Taylor, M. G. (1993). Mechanisms involved in the loss of antibody-mediated adherence of macrophages to lung-stage schistosomula of Schistosoma mansoni in vitro. Parasitology 106, 463-469.

Lewis, F. A. and Wilson, E. M. (1982). Regional and splenic lymphocyte proliferative responses of mice exposed to normal or irradiated Schistosoma mansoni cercariae. American Fournal of Tropical Medicine and Hygiene 31, 505-513.

Loukas, A., Tran, M. and Pearson, M. S. (2007). Schistosome membrane proteins as vaccines. International Fournal of Parasitology 37, 257-263.

Majid, A. A., Bushara, H. O., Saad, A. M., Hussein, M. F., Taylor, M. G., Dargie, J. D., Marshall, T. F. and Nelson, G. S. (1980). Observations on cattle schistosomiasis in the Sudan, a study in comparative medicine. III. Field testing of an irradiated Schistosoma bovis vaccine. American Fournal of Tropical Medicine and Hygiene 29, 452-455.

Mangold, B. L. and Dean, D. A. (1984). The migration and survival of gamma-irradiated Schistosoma mansoni larvae and the duration of host-parasite contact in relation to the induction of resistance in mice. Parasitology 88, 249-265. 
Mangold, B. L. and Dean, D. A. (1986). Passive transfer with serum and IgG antibodies of irradiated cercariainduced resistance against Schistosoma mansoni in mice. Fournal of Immunology 136, 2644-2648.

Mangold, B. L. and Dean, D. A. (1992). The role of IgG antibodies from irradiated cercaria-immunized rabbits in the passive transfer of immunity to Schistosoma mansoni-infected mice. American Fournal of Tropical Medicine and Hygiene 47, 821-829.

Mangold, B. L., Dean, D. A., Coulson, P. S. and Wilson, R. A. (1986). Site requirements and kinetics of immune-dependent elimination of intravascularly administered lung stage schistosomula in mice immunized with highly irradiated cercariae of Schistosoma mansoni. American Fournal of Tropical Medicine and Hygiene 35, 332-344.

Mangold, B. L. and Knopf, P. M. (1981). Host protective humoral immune responses to Schistosoma mansoni infections in the rat. Kinetics of hyperimmune serumdependent sensitivity and elimination of schistosomes in a passive transfer system. Parasitology 83, 559-574.

Mastin, A., Bickle, Q. D. and Wilson, R. A. (1985). An ultrastructural examination of irradiated, immunizing schistosomula of Schistosoma mansoni during their extended stay in the lungs. Parasitology 91, 101-110.

Mastin, A. J., Bickle, Q. D. and Wilson, R. A. (1983). Schistosoma mansoni: migration and attrition of irradiated and challenge schistosomula in the mouse. Parasitology 87, 87-102.

McLaren, D. J., Pearce, E. J. and Smithers, S. R. (1985). Site potential for challenge attrition in mice, rats and guinea pigs vaccinated with irradiated cercariae of Schistosoma mansoni. Parasite Immunology 7, 29-44.

McLaren, D. J. and Smithers, S. R. (1985). Schistosoma mansoni: challenge attrition during the lung phase of migration in vaccinated and serum-protected rats. Experimental Parasitology 60, 1-9.

McLaren, D. J. and Smithers, S. R. (1988). Serum from $\mathrm{CBA} / \mathrm{Ca}$ mice vaccinated with irradiated cercariae of Schistosoma mansoni protects naive recipients through the recruitment of cutaneous effector cells. Parasitology 97, 287-302.

McManus, D. P. and Loukas, A. (2008). Current status of vaccines for schistosomiasis. Clinical Microbiology Reviews 21, 225-242.

Miller, T. A. (1978). Industrial development and field use of the canine hookworm vaccine. Advances in Parasitology 16, 333-342.

Minard, P., Dean, D. A., Jacobson, R. H., Vannier, W. E. and Murrell, K. D. (1978a). Immunization of mice with cobalt-60 irradiated Schistosoma mansoni cercariae. American Fournal of Tropical Medicine and Hygiene 27, 76-86.

Minard, P., Dean, D. A., Vannier, W. E. and Murrell, K. D. (1978b). Effect of immunization on migration of Schistosoma mansoni through lungs. American Fournal of Tropical Medicine and Hygiene 27, 87-93.

Moloney, N. A. and Webbe, G. (1990). Antibody is responsible for the passive transfer of immunity to mice from rabbits, rats or mice vaccinated with attenuated Schistosoma japonicum cercariae. Parasitology $\mathbf{1 0 0 ,}$ 235-239.
Moser, G., Wassom, D. L. and Sher, A. (1980). Studies of the antibody-dependent killing of schistosomula of Schistosoma mansoni employing haptenic target antigens. I. Evidence that the loss in susceptibility to immune damage undergone by developing schistosomula involves a change unrelated to the masking of parasite antigens by host molecules. Fournal of Experimental Medicine 152, 41-53.

Mountford, A. P., Anderson, S. and Wilson, R. A. (1996). Induction of Th1 cell-mediated protective immunity to Schistosoma mansoni by co-administration of larval antigens and IL-12 as an adjuvant. Fournal of Immunology 156, 4739-4745.

Mountford, A. P., Coulson, P. S., Pemberton, R. M., Smythies, L. E. and Wilson, R. A. (1992). The generation of interferon-gamma-producing $\mathrm{T}$ lymphocytes in skin-draining lymph nodes, and their recruitment to the lungs, is associated with protective immunity to Schistosoma mansoni. Immunology $\mathbf{7 5}$, 250-256.

Mountford, A. P., Coulson, P. S. and Wilson, R. A. (1988). Antigen localization and the induction of resistance in mice vaccinated with irradiated cercariae of Schistosoma mansoni. Parasitology 97, 11-25.

Oswald, I. P., Caspar, P., Wynn, T. A., SchartonKersten, T., Williams, M. E., Hieny, S., Sher, A. and James, S. L. (1998). Failure of P strain mice to respond to vaccination against schistosomiasis correlates with impaired production of IL-12 and up-regulation of Th2 cytokines that inhibit macrophage activation. European Fournal of Immunology 28, 1762-1772.

Pearce, E. J., Basch, P. F. and Sher, A. (1986). Evidence that the reduced surface antigenicity of developing Schistosoma mansoni schistosomula is due to antigen shedding rather than host molecule acquisition. Parasite Immunology 8, 79-94.

Pearce, E. J., Caspar, P., Grzych, J. M., Lewis, F. A. and Sher, A. (1991). Downregulation of Th1 cytokine production accompanies induction of Th2 responses by a parasitic helminth, Schistosoma mansoni. Fournal of Experimental Medicine 173, 159-166.

Pemberton, R. M., Smythies, L. E., Mountford, A. P. and Wilson, R. A. (1991). Patterns of cytokine production and proliferation by $\mathrm{T}$ lymphocytes differ in mice vaccinated or infected with Schistosoma mansoni. Immunology 73, 327-333.

Pemberton, R. M. and Wilson, R. A. (1995). T-helper type-1-dominated lymph node responses induced in C57BL/6 mice by optimally irradiated cercariae of Schistosoma mansoni are down-regulated after challenge infection. Immunology 84, 310-316.

Radke, M. G. and Sadun, E. H. (1963). Resistance produced in mice by exposure to irradiated Schistosoma mansoni cercariae. Experimental Parasitology 13, 134-142.

Reynolds, S. R. and Harn, D. A. (1992). Comparison of irradiated-cercaria schistosome vaccine models that use 15- and 50-kilorad doses: the 15-kilorad dose gives greater protection, smaller liver sizes, and higher gamma interferon levels after challenge. Infection and Immunity 60, 90-94.

Richter, D. and Harn, D. A. (1993). Candidate vaccine antigens identified by antibodies from mice vaccinated with 15- or 50-kilorad-irradiated cercariae of 
Schistosoma mansoni. Infection and Immunity 61, 146-154.

Richter, D., Incani, R. N. and Harn, D. A. (1993a). Isotype responses to candidate vaccine antigens in protective sera obtained from mice vaccinated with irradiated cercariae of Schistosoma mansoni. Infection and Immunity 61, 3003-3011.

Richter, D., Reynolds, S. R. and Harn, D. A. (1993b). Candidate vaccine antigens that stimulate the cellular immune response of mice vaccinated with irradiated cercariae of Schistosoma mansoni. Fournal of Immunology 151, 256-265.

Sadun, E. H., Bruce, J. I. and Macomber, P. B. (1964). Parasitologic, pathologic and serologic reactions to Schistosoma mansoni in monkeys exposed to irradiated cercariae. American Fournal of Tropical Medicine and Hygiene 13, 548-557.

Sher, A., Hieny, S., James, S. L. and Asofsky, R. (1982a). Mechanisms of protective immunity against Schistosoma mansoni infection in mice vaccinated with irradiated cercariae. II. Analysis of immunity in hosts deficient in T lymphocytes, B lymphocytes, or complement. Fournal of Immunology 128, 1880-1884.

Sher, A., James, S. L., Simpson, A. J., Lazdins, J. K. and Meltzer, M. S. (1982b). Macrophages as effector cells of protective immunity in murine schistosomiasis. III. Loss of susceptibility to macrophage-mediated killing during maturation of $S$. mansoni schistosomula from the skin to the lung stage. Fournal of Immunology 128, 1876-1879.

Simpson, A. J., James, S. L. and Sher, A. (1983). Identification of surface antigens of schistosomula of Schistosoma mansoni recognized by antibodies from mice immunized by chronic infection and by exposure to highly irradiated cercariae. Infection and Immunity 41, 591-597.

Smithers, S. R. (1962). Immunizing effect of irradiated cercariae of Schistosoma mansoni in rhesus monkeys. Nature, London 194, 1146-1147.

Smithers, S. R. (1976). Immunity to trematode infections. In Immunology of Parasitic Infections (ed. Cohen, E. and Sadun, E. E.), pp. 296-332. Blackwell Scientific Publications, Oxford, UK.

Smithers, S. R. and Terry, R. J. (1965). Naturally acquired resistance to experimental infections of Schistosoma mansoni in the rhesus monkey (Macaca mulatta). Parasitology 55, 701-710.

Smithers, S. R. and Terry, R. J. (1967). Resistance to experimental infection with Schistosoma mansoni in rhesus monkeys induced by the transfer of adult worms. Transactions of the Royal Society of Tropical Medicine and Hygiene 61, 517-533.

Smyth, D., McManus, D. P., Smout, M. J., Laha, T., Zhang, W. and Loukas, A. (2003). Isolation of cDNAs encoding secreted and transmembrane proteins from Schistosoma mansoni by a signal sequence trap method. Infection and Immunity 71, 2548-2554.

Smythies, L. E., Betts, C., Coulson, P. S., Dowling, M. A. and Wilson, R. A. (1996). Kinetics and mechanism of effector focus formation in the lungs of mice vaccinated with irradiated cercariae of Schistosoma mansoni. Parasite Immunology 18, 359-369.
Smythies, L. E., Coulson, P. S. and Wilson, R. A. (1992a). Monoclonal antibody to IFN-gamma modifies pulmonary inflammatory responses and abrogates immunity to Schistosoma mansoni in mice vaccinated with attenuated cercariae. Fournal of Immunology 149, 3654-3658.

Smythies, L. E., Pemberton, R. M., Coulson, P. S., Mountford, A. P. and Wilson, R. A. (1992b).

$\mathrm{T}$ cell-derived cytokines associated with pulmonary immune mechanisms in mice vaccinated with irradiated cercariae of Schistosoma mansoni. Fournal of Immunology 148, 1512-1518.

Soisson, L. A., Reid, G. D., Farah, I. O., Nyindo, M. and Strand, M. (1993). Protective immunity in baboons vaccinated with a recombinant antigen or radiation-attenuated cercariae of Schistosoma mansoni is antibody-dependent. Fournal of Immunology 151, 4782-4789.

Soisson, L. M., Masterson, C. P., Tom, T. D., McNally, M. T., Lowell, G. H. and Strand, M. (1992). Induction of protective immunity in mice using a 62-kDa recombinant fragment of a Schistosoma mansoni surface antigen. Fournal of Immunology 149 , 3612-3620.

Stek, M., Jr., Dean, D. A. and Clark, S. S. (1981 a). Attrition of schistosomes in an irradiation-attenuated cercarial immunization model of Schistosoma mansoni. American Zournal of Tropical Medicine and Hygiene 30, 1033-1038.

Stek, M. F., Minard, P., Dean, D. A. and Hall, J. E. $(1981 b)$. Immunization of baboons with Schistosoma mansoni cercariae attenuated by gamma irradiation. Science 212, 1518-1520.

Sturrock, R. F., James, C., James, E. R. and Webbe, G. (1980). Immunization of baboons (Papio anubis) against Schistosoma haematobium with irradiated cercariae or schistosomula. Transactions of the Royal Society of Tropical Medicine and Hygiene 74, 834-835.

Taylor, M. G. (1994). Schistosomiasis vaccines: Farewell to the God of Plague? Fournal of Tropical Medicine and Hygiene 97, 257-268.

Taylor, M. G., James, E. R., Nelson, G. S., Bickle, Q., Andrews, B. J., Dobinson, A. R. and Webbe, G. (1976a). Immunisation of baboons against Schistosoma mansoni using irradiated S. mansoni cercariae and schistosomula and non-irradiated $S$. rodhaini cercariae. Fournal of Helminthology 50, 215-221.

Taylor, M. G., James, E. R., Nelson, G. S., Bickle, Q., Dunne, D. W. and Webbe, G. (1976b). Immunisation of sheep against Schistosoma mattheei using either irradiated cercariae or irradiated schistosomula. Fournal of Helminthology 50, 1-9.

Tran, M. H., Pearson, M. S., Bethony, J. M., Smyth, D. J., Jones, M. K., Duke, M., Don, T. A., McManus, D. P., Correa-Oliveira, R. and Loukas, A. (2006). Tetraspanins on the surface of Schistosoma mansoni are protective antigens against schistosomiasis. Nature Medicine 12, 835-840.

Vignali, D. A., Bickle, Q. D. and Taylor, M. G. (1988a). Studies on immunity to Schistosoma mansoni in vivo: whole-body irradiation has no effect on vaccine-induced resistance in mice. Parasitology 96, 49-61.

Vignali, D. A., Bickle, Q. D., Taylor, M. G., Tennent, G. and Pepys, M. B. $(1988 b)$. Comparison of the role of 
complement in immunity to Schistosoma mansoni in rats and mice. Immunology 63, 55-61.

Vignali, D. A., Crocker, P., Bickle, Q. D., Cobbold, S., Waldmann, H. and Taylor, M. G. (1989a). A role for CD4 + but not CD8 + T cells in immunity to Schistosoma mansoni induced by 20 krad-irradiated and Ro 11-3128-terminated infections. Immunology 67, 466-472.

Vignali, D. A., Klaus, S. N., Bickle, Q. D. and Taylor, M. G. (1989b). Histological examination of the cellular reactions around schistosomula of Schistosoma mansoni in the lungs of sublethally irradiated and unirradiated, immune and control rats. Parasitology $\mathbf{9 8 ,}$ $57-65$.

Villella, J. B., Gomberg, H. J. and Gould, S. E. (1961). Immunization to Schistosoma mansoni in mice inoculated with radiated cercariae. Science 134, 1073-1075.

Von Lichtenberg, F., Correa-Oliveira, R. and Sher, A. (1985). The fate of challenge schistosomula in the murine anti-schistosome vaccine model. American Fournal of Tropical Medicine and Hygiene 34, 96-106.

Webbe, G., Sturrock, R. F., James, E. R. and James, C. (1982). Schistosoma haematobium in the baboon (Papio anubis): effect of vaccination with irradiated larvae on the subsequent infection with percutaneously applied cercariae. Transactions of the Royal Society of Tropical Medicine and Hygiene 76, 354-361.

Wilson, R. A. and Coulson, P. S. (1989). Lung-phase immunity to Schistosomes: a new perspective on an old problem? Parasitology Today 5, 274-278.

Wilson, R. A. and Coulson, P. S. (2006). Schistosome vaccines: a critical appraisal. Memórias do Instituto Oswaldo Cruz 101 (Suppl. 1), 13-20.

Wilson, R. A., Coulson, P. S., Betts, C., Dowling, M. A. and Smythies, L. E. (1996). Impaired immunity and altered pulmonary responses in mice with a disrupted interferon-gamma receptor gene exposed to the irradiated Schistosoma mansoni vaccine. Immunology 87, 275-282.

Wilson, R. A., Coulson, P. S. and Dixon, B. (1986). Migration of the schistosomula of Schistosoma mansoni in mice vaccinated with radiation-attenuated cercariae, and normal mice: an attempt to identify the timing and site of parasite death. Parasitology 92, 101-116.

Wynn, T. A., Jankovic, D., Hieny, S., Cheever, A. W. and Sher, A. (1995). IL-12 enhances vaccine-induced immunity to Schistosoma mansoni in mice and decreases T helper 2 cytokine expression, IgE production, and tissue eosinophilia. Fournal of Immunology 154, 4701-4709.

Wynn, T. A., Oswald, I. P., Eltoum, I. A., Caspar, P., Lowenstein, C. J., Lewis, F. A., James, S. L. and Sher, A. (1994). Elevated expression of Th1 cytokines and nitric oxide synthase in the lungs of vaccinated mice after challenge infection with Schistosoma mansoni. Fournal of Immunology 153, 5200-5209.

Wynn, T. A., Reynolds, A., James, S., Cheever, A. W., Caspar, P., Hieny, S., Jankovic, D., Strand, $M$. and Sher, A. (1996). IL-12 enhances vaccine-induced immunity to schistosomes by augmenting both humoral and cell-mediated immune responses against the parasite. Fournal of Immunology 157, 4068-4078.

Yole, D. S., Reid, G. D. and Wilson, R. A. (1996). Protection against Schistosoma mansoni and associated immune responses induced in the vervet monkey Cercopithecus aethiops by the irradiated cercaria vaccine. American Fournal of Tropical Medicine and Hygiene 54, 265-270. 